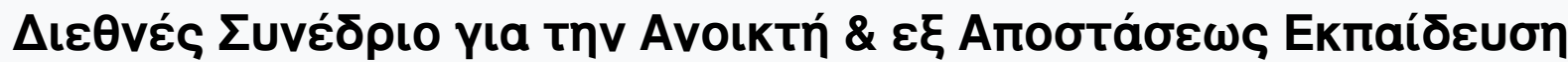

Tóp. 5, Ap. 3B (2009)

Open and Distance Education for Global Collaboration \& Educational Development

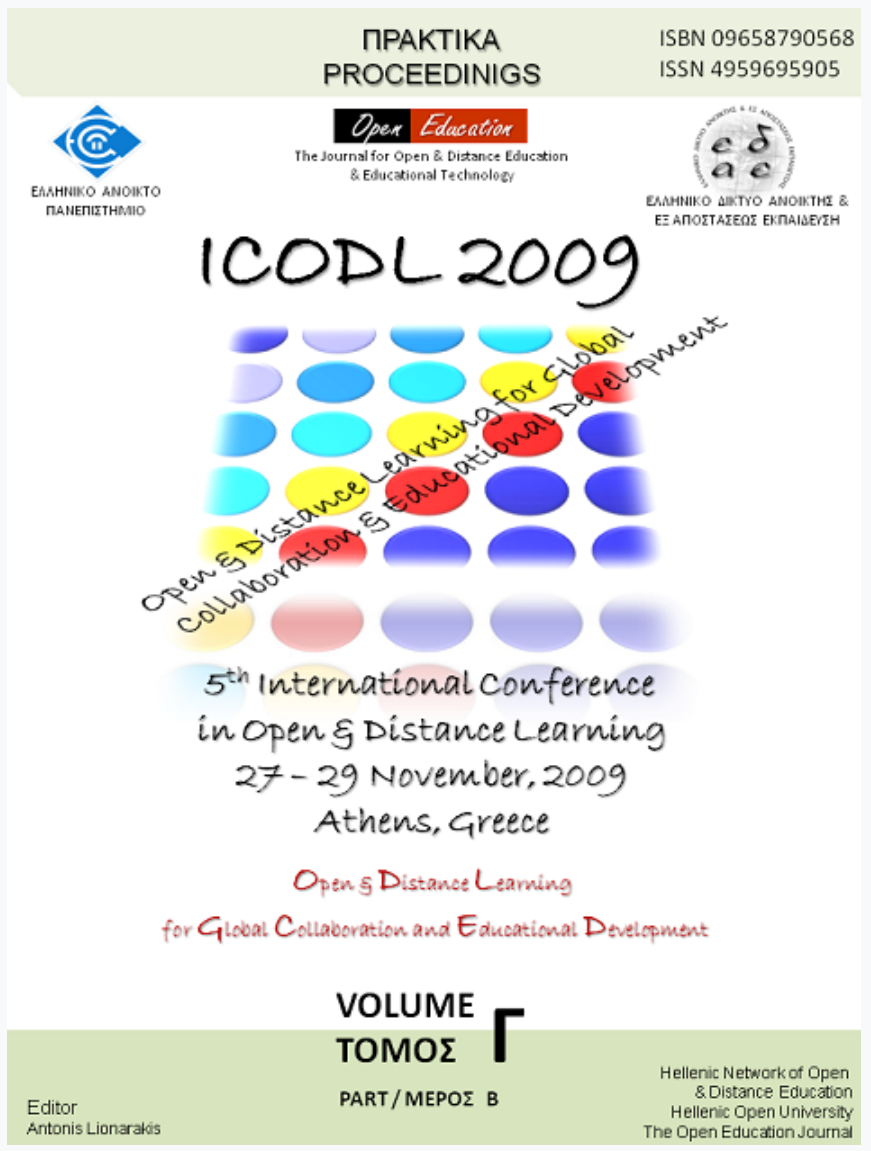

Visualization in the multimedia course of Russian (MESI participating in ELBEP project)

Tatyana LOGUTENKOVA

doi: $10.12681 /$ icodl. 520 


\title{
Visualization in the multimedia course of Russian (MESI participating in ELBEP project)
}

\author{
Tatyana LOGUTENKOVA,
}

\author{
Doctor of Philology, \\ Professor of Foreign Languages of Moscow State University of Economics, \\ Statistics and Informatics (MESI), Tver Branch; \\ logoutenkova@hotmail.com
}

\begin{abstract}
Developing the portal of Russian for ELBEP project («Eliminating Language Barriers in European Prisons through Open and Distance Learning Technologies») the work group of Moscow State University of Economics, Statistics and Informatics (MESI) considered its primary goal to create a set of visualization means facilitating students to acquire knowledge through e-learning technologies. We carried out. We visualize a number of learning tools: print materials; Flash-animations; exercises; videos; tests using icons, at the bottom of the portal page. The main character of Flash-animations is a «teaching/learning object» possessing essential features similar to and acting as a human being, so it helps to visualize meanings of words and phrases introduced in the course. For certain didactic purposes tables, photos, pictures, drawings, etc. were used. Pointing at a certain object of reality is the gesture which helps a teacher in face-to-face communication to attract student's attention. We use color, size, motion or their combinations to point at a certain image for a student to understand what exactly is meant when he or she hears the sound pattern of a word, word-from or phrase. Videos are samples of everyday communication and the scenery helps to visualize the meaning of dialogues.
\end{abstract}

ELBEP Project «Eliminating Language Barriers in European Prisons through Open and Distance Learning Technologies» was initiated in October, 2007 and is coordinated by Anadolu University (Turkey). All member teams (they are Anadolu University (Turkey), EADTU, EDEN, Linguapolis (Belgium), Innowacja Foundation (Poland), Hellenic Open University (Greece), Dr. Wolfram Laaser and Moscow State University of Economics, Statistics and Informatics (MESI)) have got vast experience in distance and e-learning, creation of e-courses. The project is aimed at producing electronic portals of Turkish, Polish, Greek, Spanish and Russian languages. The target group of the project is prison staff of penitentiary institutions in Belgium, Greece and Germany. The target group is interested in learning foreign languages in order to communicate with prisoners of different nationalities. The task of MESI team is to develop an electronic portal of the Russian Language.

Starting to create the portal of the Russian language we confessed how difficult the task was. It is common knowledge that learning foreign languages is successful only if it possible to create a proper language environment, which imitates a real communication. When learning languages is not possible in the natural language environment that is in the country where a learner has to acquire foreign language skills to survive in day-to-day communication, the most traditional way of imitating it is face-to-face communication between a student and a teacher. The role of the latter 
is even wider than a partner in communication, as the teacher uses every possible means to introduce new words and phrases, explain what is difficult for understanding, answer all sorts of questions a student may have while learning a foreign language. Following a monolingual approach, which is approved by the majority of professional teachers of foreign languages, a teacher resorts to gestures, postures, mimic expressions, intonation, etc. helping the student to guess the meaning of a new lingual item. Usually while working with beginners a teacher uses lots of additional materials such as pictures, drawings, photos, various objects of reality (e.g. balls, small sculptures, toys, vegetables, etc.) to illustrate the meaning of a word. This set of means helps to visualize the lingual meaning and hence may be referred to as visualization means. In face-to-face teaching both the choice and the use of the means depends on a teacher's skills and abilities. Surely, the application of the means is different with different groups of students, depending on their age, sex, traits of character, etc. Each time a teacher makes a decision which set to use taking into account not only his or her own preferences but also wishes and attitudes of the students.

Teaching a foreign language through distance and e-learning technologies presupposes that the participation of a teacher or a tutor is rather limited. That is why we have to think of a number of instruments and tools to substitute the teacher but still provide a student with all the necessary means for successful learning. In fact it would be a mistake to see e-learning or e-teaching of a foreign language as the next stage in teaching languages, it should be considered as another attempt to create a language environment which is more or less similar to a natural one. However, we may and should take into account all the achievements of face-to-face teaching while developing an e-learning environment for language teaching. One of these achievements which should be thoroughly analyzed by linguists, teachers and psychologists is the conventions of face-to-face teaching foreign languages. In spite of the fact that pictures, drawings, etc. can hardly be equal to real objects, because they are conventional and may be due to that they serve as mnemonic instruments, stimulating our mind and memory by their strangeness and unreal features.

Attempts to imitate natural language environment have been made when TV was adapted for learning languages. The teacher of a foreign language participating in TV educational program behaves himself as he usually does in face-to-face teaching, more than that TV program includes fragments of real communication, specially directed fragments of real life communication. The only drawback of these programs is the absence of teacher's control and supervision of student's apprehension and acquiring new knowledge. This drawback can be compensated when we turn to elearning technologies providing interactive mode of communication between a teacher or a tutor and a student.

Bearing all above mentioned in mind we started to develop the portal of the Russian language and formulated our primary goal as creating a whole set of visualization means of lingual meanings.

Language portal development was divided into several stages. First we carried out a number of learning tools the combination of which produces the structure of the portal and the arrangement of language e-learning. Developing the learning tools we took 
into consideration the experience of our Turkish colleagues who created an e-portal of Turkish. The learning tools which form both the structure of the Russian portal and language e-learning are as follows:

1. Print materials (both Flash- and PDF-formats).

2. Flash-animations.

3. Exercises.

4. Videos.

5. Tests.

The first four tools are the structural parts of the language portal, while the fifth is done in Prometheus System of Distance learning, the educational platform we use to arrange language e-learning.

To visualize the learning tools which are the structural parts of the Russian language portal we use a number of icons, placed at the bottom of the portal page, as you see in the screenshot below.
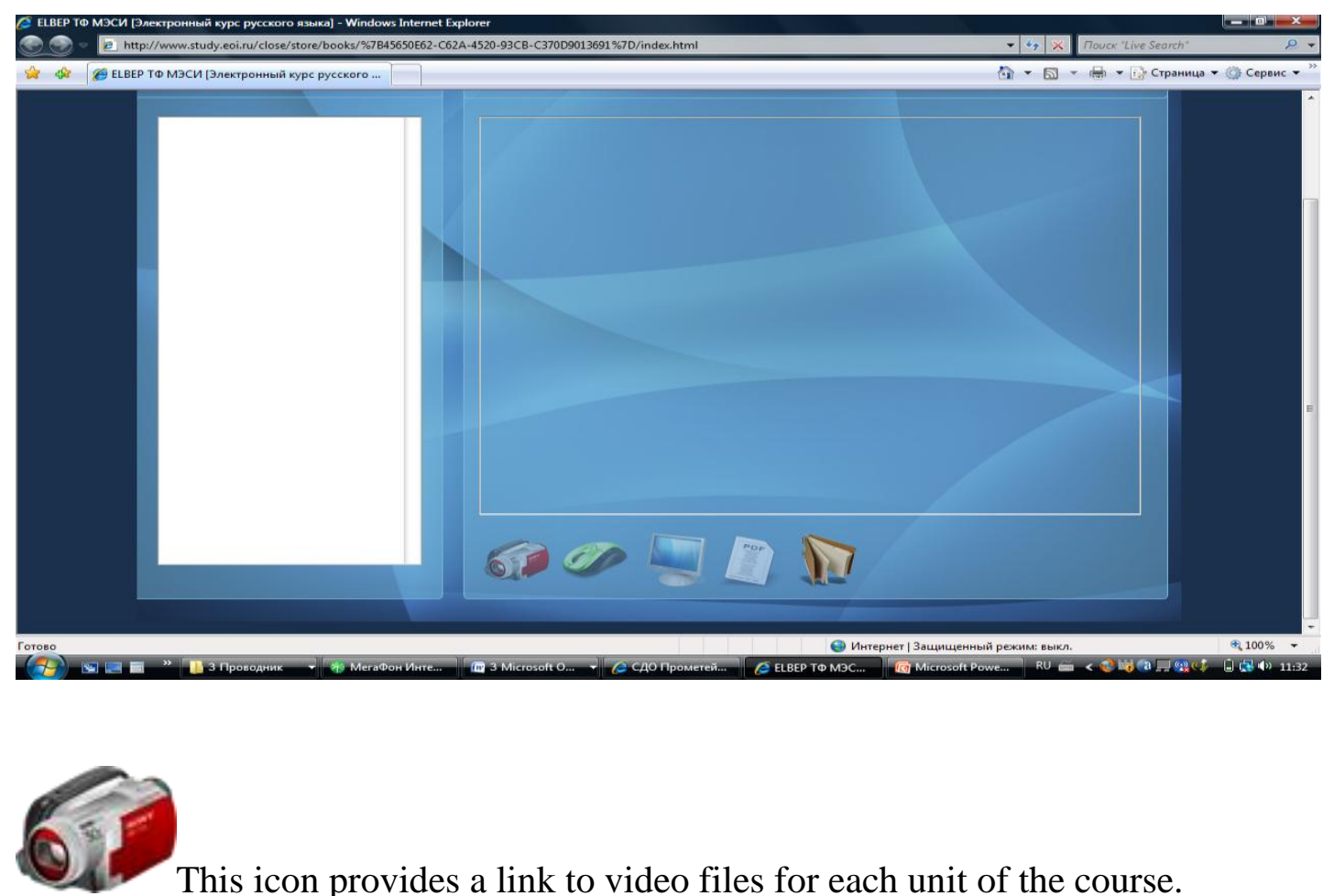

This icon provides a link to video files for each unit of the course.

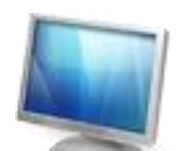

This icon provides a link to Flash-animations introducing language items each of which is provided with an audio file.

This icon provides a link to exercises helping to train and test the acquired language skills. 


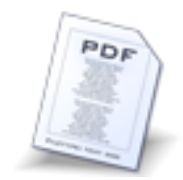

This icon provides a link to print materials in PDF-format with illustrations made in the same style as those used in Flash-animations.

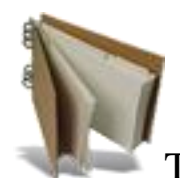

This icon is introduced to provide a link to the Homepage of MESI where a student may get help, as it contains instructions how to log in for learning, how to use Prometheus System of Distance Learning (PowerPoint presentation), how to work with the portal of the Russian Language (PowerPoint presentation), how to ask a question to the tutor, etc.

The main character of our Flash-animations is a «teaching/learning object» (as we call it) possessing some essential features similar to a human being. We have chosen a really symbolic conventional object different from a real human being first because of technical considerations. But this object turns out to be a really good choice as its conventionality and brightness help to focus student's attention on learning much better. Pilot application of our portal (July, 1-31 2009) has given more evidence for this conclusion, as our students mentioned that the approach followed in Flashanimations help them much to understand the meaning of words and wordcombinations.

«Teaching/learning object» (it is teaching as being used for teaching a language, and it is learning because it imitates a learner in our scenarios being the basis for every unit of the course)

can be

large and small,

tall and not tall,

fat and thin.

It may have

age characteristics,

sex differences,

elements of appearance similar to a human being (eyes, mouth, nose, etc.)

This «teaching/learning object» is used in various functions. It demonstrates essential characteristics of a human being. It supervises the process of learning being a substitute for a teacher, it points at objects of reality, pictures, etc. It or rather they (as we may modify them and produce an endless number if necessary) participate in the dialogues and pronounce monologues.

Further, there is a screenshot illustrating different varieties of our teaching/learning objects: 


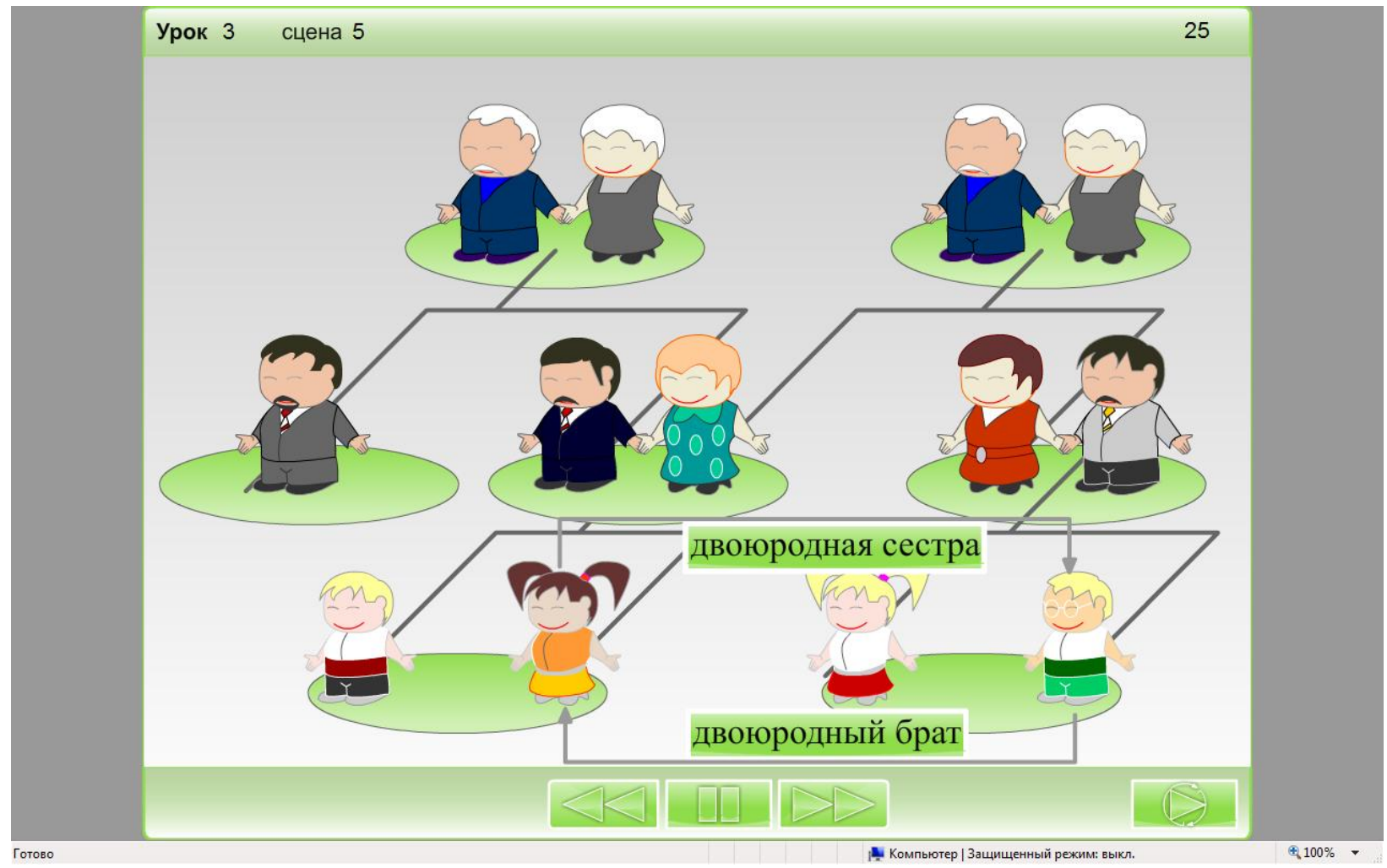

Apart from teaching/learning objects for certain didactic purposes we use tables, photos, graphic pictures, etc. A sample of these additional means is shown below:

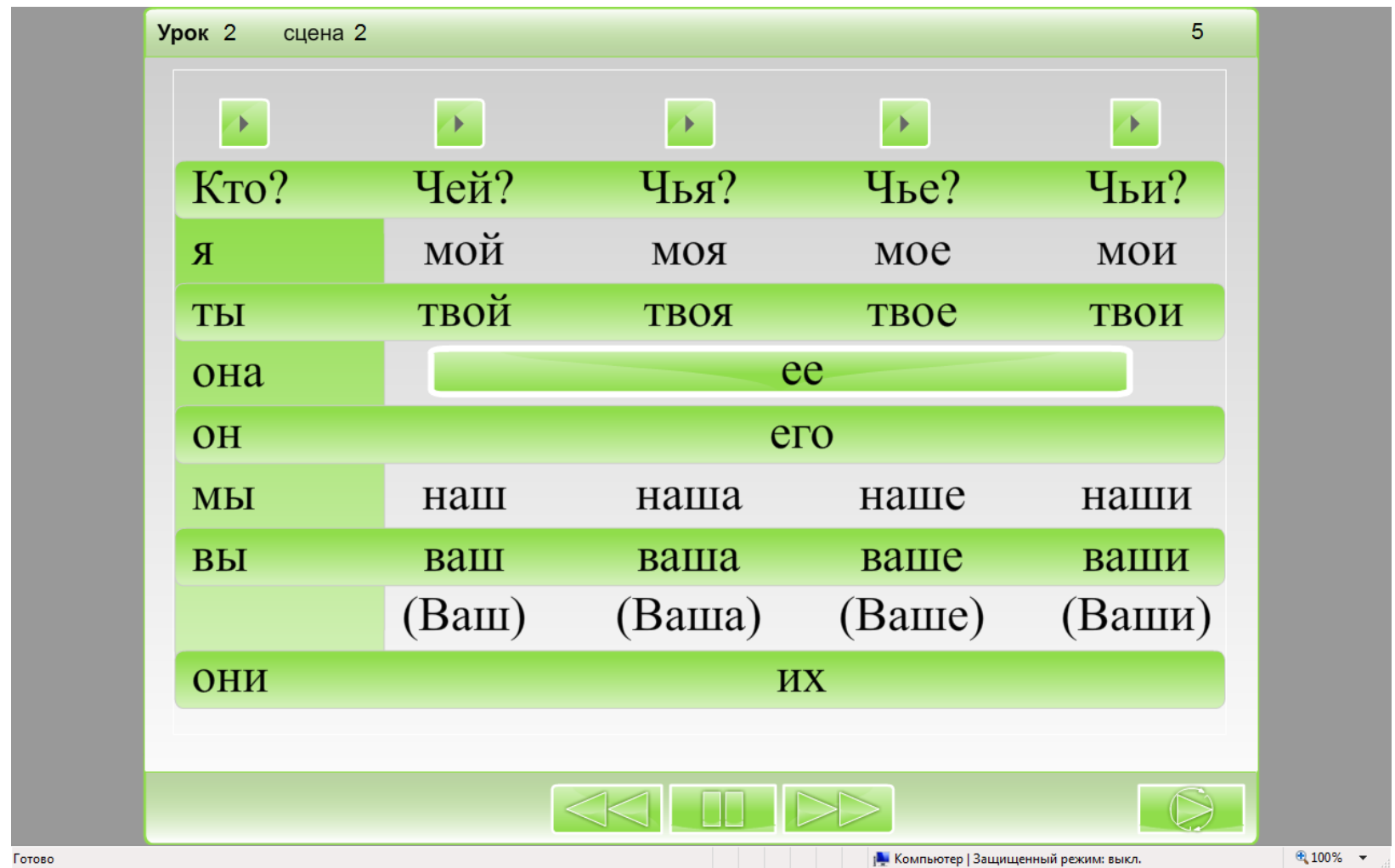

Pointing at a certain object of reality is the gesture which helps a teacher in face-toface communication to attract student's attention to the object using it as a means to denote the meaning of a word or word-combination new for a student. Flash 
technology helps us to produce not only static but also moving images. While developing the portal we use a number of means - color, size, motion - or their combinations to point at a certain image for a student to understand what exactly is meant when he or she hears the sound pattern of a word, word-from or a phrase. Further, there are some screenshots illustrating «means of pointing at»:

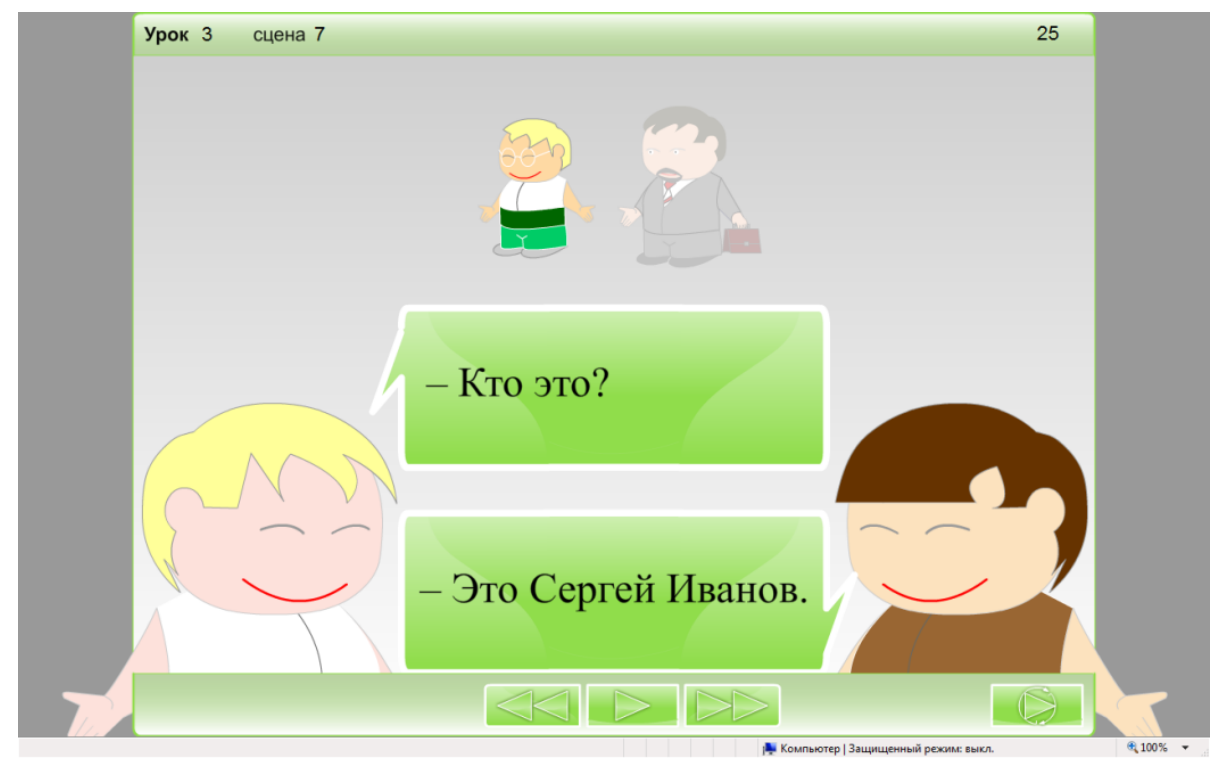

For pointing at size and colour are used.

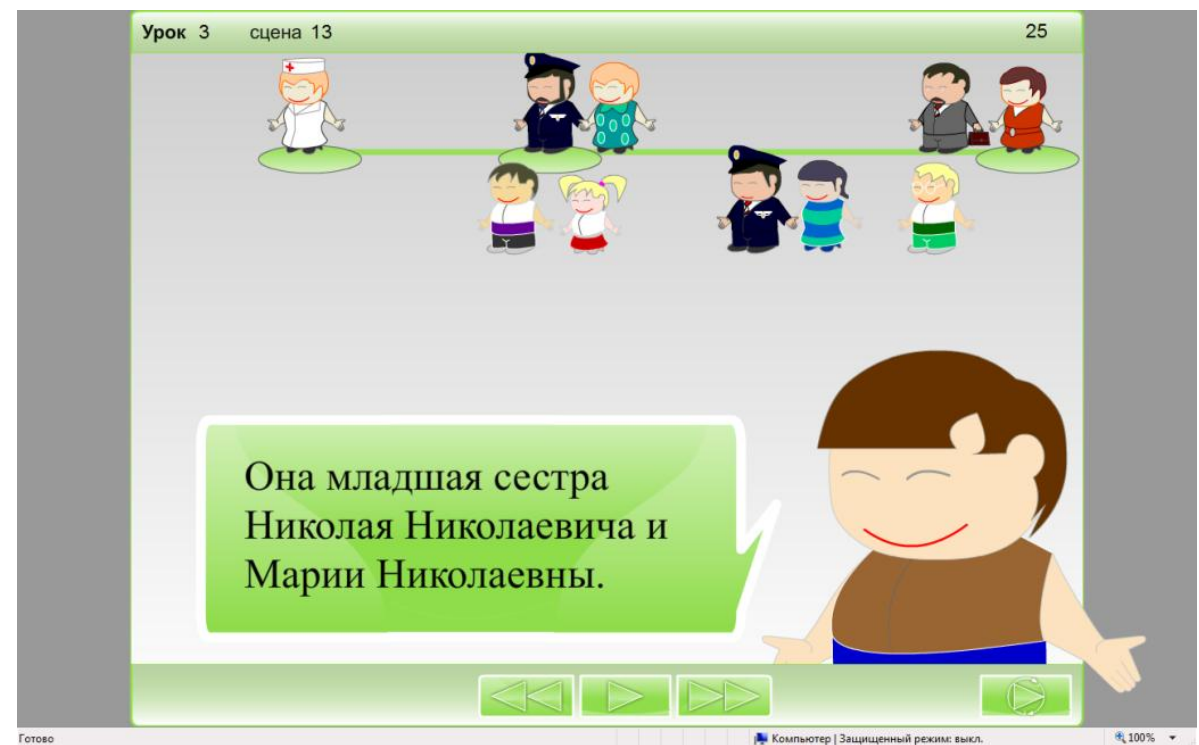

Size, colour, motion and additional graphic means of pointing at are used. 


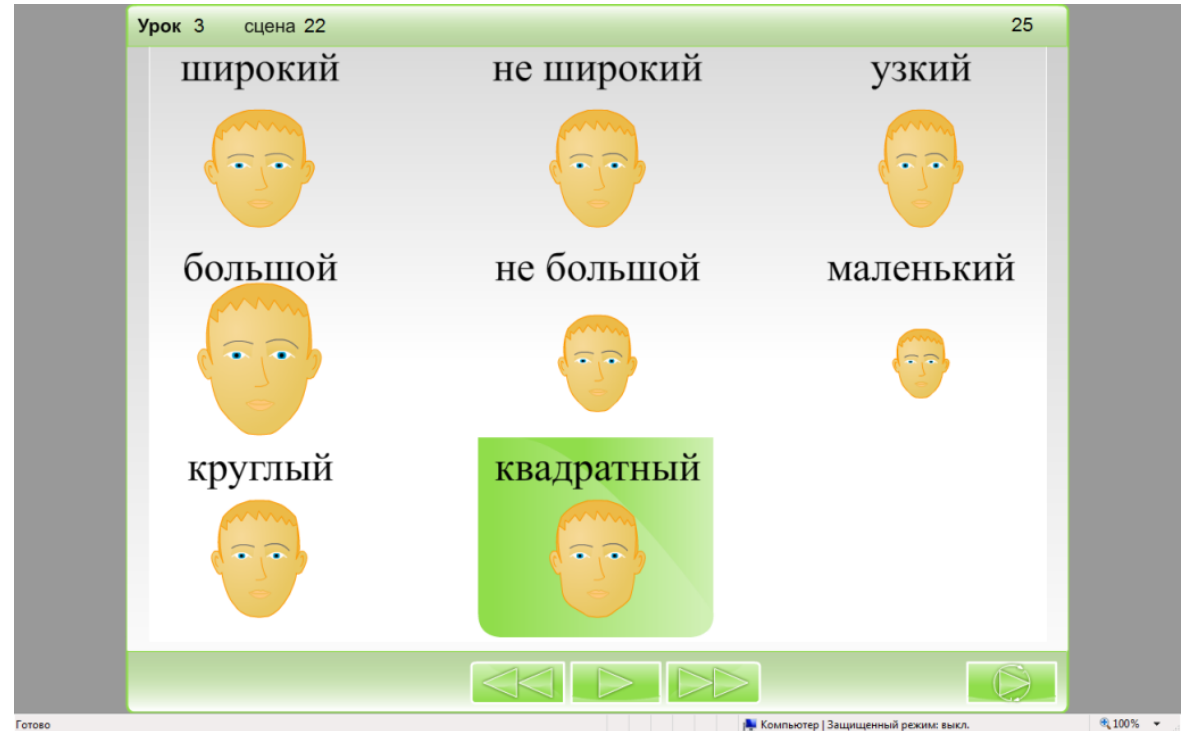

Here we also use size, colour, motion and additional graphic means.

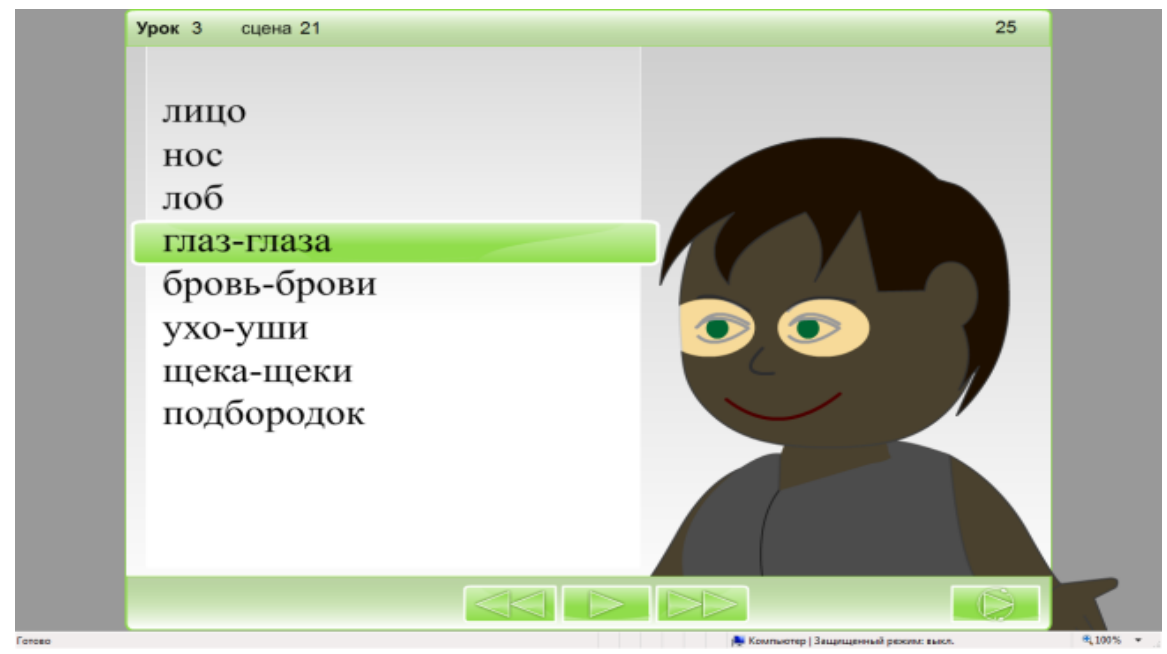




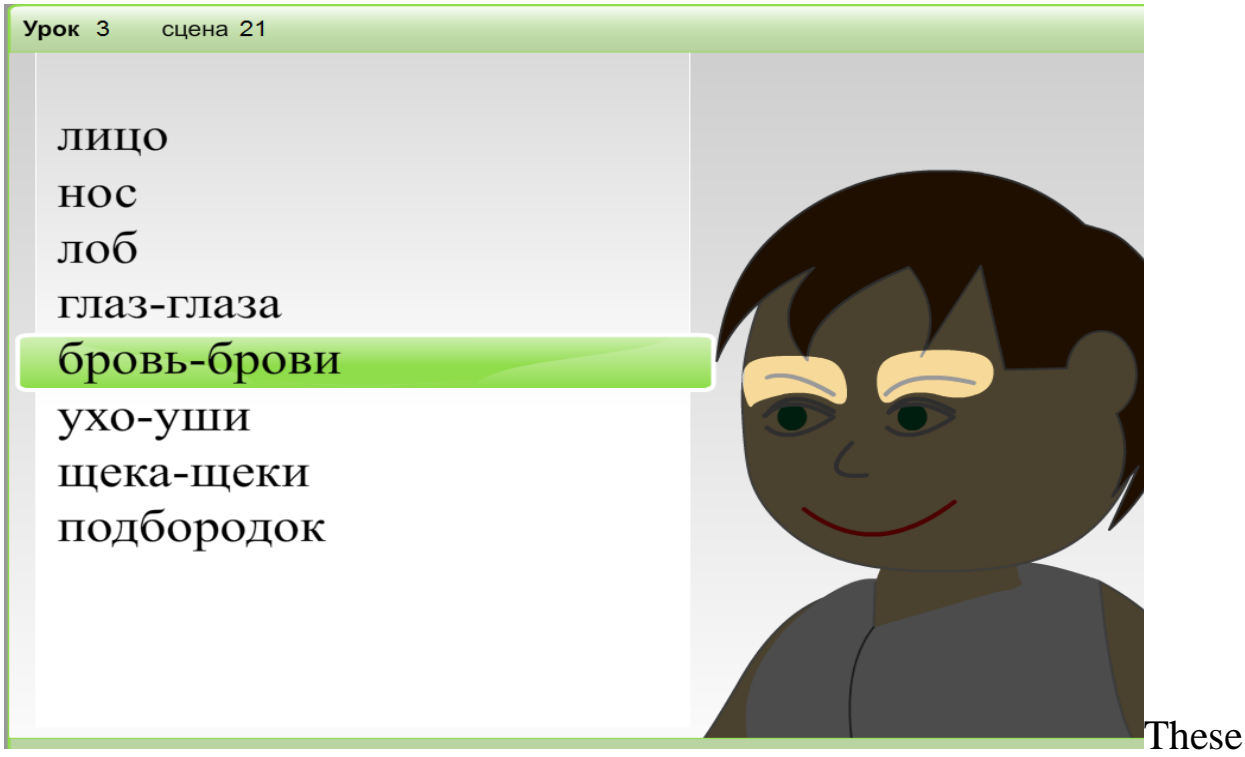

screenshots illustrate how we use motion and colour to point at a certain fragment of the page.

We include video as a separate learning tool. Videos are samples of everyday communication and their function is primarily illustrative as the scenery helps to visualize the meaning of dialogues. Below, there is scene from the video «Interview in the office»:

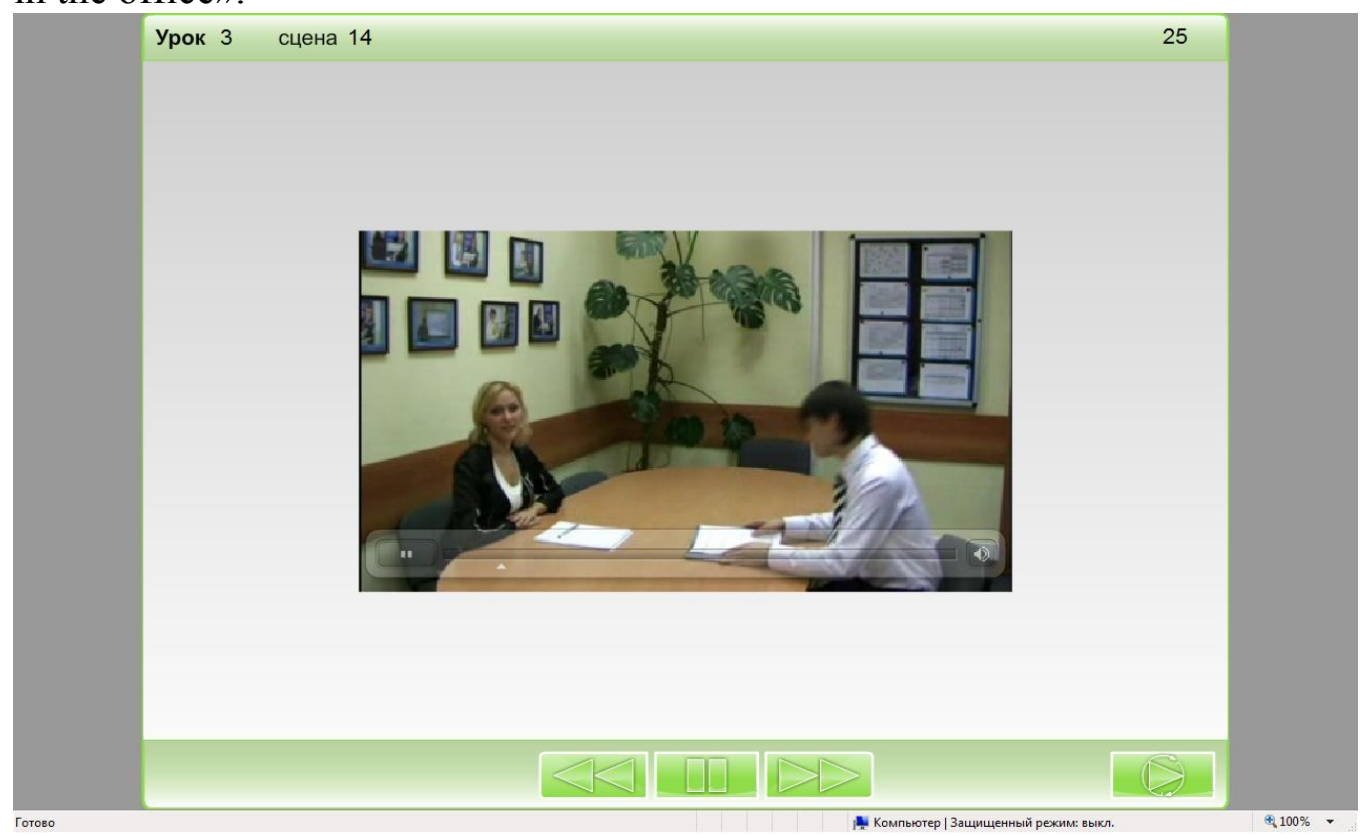

Having introduced a set of e-specific means of visualization we do understand that still a student may have some questions about the content of the course. That is why we consider tutor's support to be an essential part of e-learning. As we place the portal of the Russian language within Prometheus System of Distance Learning which provides a number of functions to arrange interaction between a student and a tutor, we offer our students the following forms of tutor's support:

- Forums

- Chat sessions 
- File exchange

Apart from the functions provided by Prometheus we also arrange tutor's support in the form of video conferences through Skype or Click-to-Meet. The last form of the tutor's support can also be referred to the means of visualization.

Having developed the portal of the Russian language we tested our approaches in the pilot application of ELBEP project. The experience we got may be used both for developing other language portals and arranging language e-learning. 